РЕЦЕНЗИИ, ХРОНИКА, ИНФОРМАЦИЯ

УДК 39.21.571.13

ISSN 1609-0683

DOI: https://doi.org/10.17308/geo.2021.4/3756

\title{
История хозяйственного освоения озера Эбейты
}

\author{
В.Н. Демешко \\ Омский государственный педагогический университет, Омск, Россия \\ (644043, г. Омск, ул. Набережсная Тухачевского, 14)
}

\begin{abstract}
Аннотация: Цель данного исследования - проследить последовательность изучения, проектирования и хозяйственной деятельности на озере Эбейты с первой половины XX века до настоящего времени, выявив время главных изменений в характере природопользования.

В статье рассматривается роль озера Эбейты в хозяйственной деятельности Омского Прииртышья. Предметом исследования стали реализованные и нереализованные проекты и идеи по использованию озера в промышленности, транспортной и рекреационной сфере, рациональном природопользовании. В статье представлены географические параметры озера, указаны его природные ресурсы, дана обобщающая характеристика развития проектов и идей по мере исследования акватории озера, его природы и экологического состояния. Подчеркнуты ключевые этапы смены характера и вектора природопользования. Результаты показывают степень вовлечения озера в хозяйственную деятельность в разные исторические эпохи, а также изменения видов природопользования по мере возникновения экологических проблем. Особое внимание уделено довоенному этапу его изучения, подготовке к эксплуатации, и добыче минерального сырья в годы Великой Отечественной войны, так как именно в это время озеро подвергалось наибольшему антропогенному воздействию. В последующее время озеро стало местом природоохранной и туристско-рекреационной деятельности, одним из наиболее перспективных объектов для проектирования в области экологического туризма. Исследование истории проектирования на озере Эбейты позволяет лучше понять антропогенные процессы, происходящие в горько-соленых озерах степной полосы Российской Федерации. Способствует более качественному территориальному планированию, и в будущем может выступать фундаментом для формирования концепции рационального природопользования и устойчивого развития аналогичных акваторий, прилегающих к ним населенных пунктов, объектов промышленной, транспортной и рекреационной инфраструктуры.
\end{abstract}

Ключевые слова: проектирование, природные ресурсы, озеро, рациональное природопользование, заказник.

Для цитирования: Демешко В.Н. История хозяйственного освоения озера Эбейты // Вестник Воронежского государственного университета. Серия: География. Геоэкология, 2021, № 4, с. 100-105. DOI: https://doi.org/10.17308/geo.2021.4/3756

\section{ВВЕДЕНИЕ}

Омская область - регион России, расположенный на юге Западно-Сибирской равнины. Его роль в народном хозяйстве страны представлена развитым промышленным, сельскохозяйственным и транспортным комплексом. В последние годы развитие получила и сфера услуг, в том числе рекреация и туризм. Все это способствовало вовлечению природных объектов региона (геологической среды, гидрологической сети, почвенного покрова, флоры и фауны) в активное хозяйственное освоение.
Из гидрологических природных объектов наиболее значимыми для хозяйства являются реки, в особенности река Иртыш. Роль озер значительно скромнее. И, хотя в регионе их более шестнадцати тысяч, в хозяйственную деятельность включены лишь некоторые из них. Так, озеро Ик является объектом рыбного промысла, озеро Ульжай - источником лечебных грязей и биологического сырья, а озеро Ленево - центром туристско-рекреационной деятельности.

(C) Демешко В.Н., 2021

凶 Демешко Виталий Николаевич, e-mail: demits517@mail.ru

Контент доступен под лицензией Creative Commons Attribution 4.0 License. 
Однако ни одно из озер Омской области не было столь значимо для экономической жизни региона, как озеро Эбейты. Будучи одной из крупнейших акваторий юга Западной Сибири, Эбейты в разные годы выступало объектом промышленной и рекреационной деятельности, а в настоящее время является местом добычи биологического сырья и точкой притяжения туристов и экскурсантов. Озеро обладает уникальными природными ресурсами: запасами мирабилита, галита и лечебных грязей. Это место обитания рачков Artemia Salina. Озеро окружено живописными ландшафтами соляной пустыни и галофитной степи. К географическим особенностям водоема относятся высокая соленость, достигающая в отдельные годы $300 \%$, небольшая глубина, не превышающая 1,6 м, незамерзаемость, а также значительные колебания площади - от 63 до $85 \mathrm{\kappa м}^{2}$ [2].

В разное время озеро было объектом изучения, планирования, проектирования и природопользования. Активная сельскохозяйственная деятельность, создание дамб, сокращение поверхностного стока, и другие антропогенные факторы способствовали частичному сокращению водного зеркала и расширению соляной пустыни в озерной котловине, что вызвало ухудшение экологического состояния природного комплекса, и создало необходимость принятия активных природоохранных мер. В 2012 году был создан комплексный природный заказник регионального значения «Озеро Эбейты», ознаменовав тем самым новый этап природопользования, природообустройства и проектирования.

\section{МАТЕРИАЛЫ И МЕТОДЫ}

Историко-географические исследования хозяйственного использования акваторий могут опираться на научный анализ данных из архивных фондов, литературно-публицистических источников, официальных отчетов. Используемые при таком анализе обобщения позволяют не только проследить динамику вовлечения гидрологического объекта в хозяйственную деятельность, но и выявить его специфические особенности, выступающие основой для исторической периодизации.

\section{ОБСУЖДЕНИЕ РЕЗУЛЬТАТОВ}

Начало природопользования на озере Эбейты относится к началу $\mathrm{XX}$, а, возможно, и к концу XIX века. Отсутствие должной системы здравоохранения в то время способствовало использованию рапы и грязей озера местными жителями для самолечения. О лечебных свойствах озера было хорошо известно, и это стало причиной в 19131914 годах возникновения первого из известных проектов создания на озере бальнеологического курорта. Инициатором проекта выступило Министерство земледелия Российской Империи. На западном берегу озера, рядом с бывшей деревней Приморской, был выбран подходящий участок, и на его границах установлены межевые столбы. Но реализовать проект не удалось вследствие начавшейся Первой Мировой войны ${ }^{1}$.

В последующие годы лечебные свойства озера продолжали привлекать больных со всей Сибири, а также из Казахстана, Забайкалья, Урала, Европейской части России, что способствовало новым предложениям для его курортно-оздоровительного использования. Главным местом купания и принятия грязевых ванн в то время был песчаный пляж в северной части акватории, вблизи деревни Ксеньевки. По наблюдениям омского химика А.П. Успенского 29 июля 1928 года в Ксеньевке было 15 подвод с приезжими, а на пляже занимались самолечением не менее 70 человек ${ }^{2}$.

В мае-июне 1930 года озеро посетила специальная рекогносцировочная комиссия в составе Председателя Окрплана К.А. Баранова, геолога П. Л. Драверта и химика А.П. Успенского, которая, поддержав идею создания курорта, пришла к заключению о возможности добычи на озере глауберовой соли. При этом особо подчеркивалась близость к озеру железной дороги, существенно облегчавшей вывоз добываемого сырья ${ }^{3}$.

Важнейший ресурс, каким выступает мирабилит, сразу же сделал приоритетным геологическое изучение озера. В течение 1930-х годов его неоднократно исследовали экспедиции Западно-Сибирского геологоразведочного треста (1931 и 1936) и Института органической и неорганической химии Академии Наук СССР (1933, 1939-1940). Однако предложений по про-

${ }^{1}$ Успенский А.П. Озеро Эбейты - будущий курорт и сырьевая база для химической промышленности. // Народное хозяйство Омской области. Орган Омской областной плановой комиссии областного управления народнохозяйственного учета, 1935, № 3, с. 51-60.

${ }^{2}$ Успенский А. Целебное озеро Эбейты в Исиль-Кульском районе. // Рабочий Путь, 1928, 23 августа, № 195 (2145), с. 4.

${ }^{3}$ Драверт П. Л. На озере Эбейты. // Рабочий Путь, 1930, 5 июня, № 124 (2674), с. 2. 
мышленному использованию озера они не выдвигали ${ }^{4}$.

Большую работу по возможностям разработки месторождения провел географ С.Р. Лаптев. Он исходил из того, что большая часть мирабилита залегает в озере в виде иловых отложений, а значит вести добычу обычными методами невозможно. К тому же на Эбейты были и другие специфические условия, усложняющие такую добычу: незначительные глубины, маломощность пласта и его загрязненность, и наличие вязкого и топкого дна. По мнению Лаптева, разработку пластов можно вести лишь после дробления их взрывами, и извлекать мирабилит на поверхность с использованием специального экскаватора. Но из-за топкого ила работа механизмов будет затруднена, равно как и транспортировка соли к берегу в условиях мелководья. В итоге Лаптев пришел к выводу об использовании только той части ресурсов, которые содержатся в рапе, и предлагает метод бассейнизации, то есть перекачки рапы в летнее время (при максимальном содержании соли) в специальные бассейны с бортами значительной высоты и толщины, после чего в течение года в них происходит сезонная садка. После ее окончания вода перекачивается в другие бассейны, или обратно в озеро, а оставшаяся на дне зимняя садка собирается и отправляется на переработку. В качестве такого бассейна С.Р. Лаптев предлагал использовать залив в восточной части озера, названный впоследствии Сагским заливом (лагуной).

По мнению С. Р. Лаптева, комплексная эксплуатация ресурсов озера могла быть дополнена и добычей брома. Однако, из трех приводимых им методов извлечения этого компонента из рапы (прямого осаждения, колонны Кубиерского и продувки воздухом), Лаптев не отдавал предпочтения ни одному из них. Он отмечал, что окончательный вариант может быть выбран лишь после проверки опытных и полузаводских установок непосредственно на озере. Лаптев допускал возможность создания на озере Эбейты большого химического комбината межобластного значения, а также предлагал провести мимо озера железнодорожную трассу, улучшив тем самым транспортно-географическое положение водоема. Проблему обеспе- чения производства пресной водой, по мнению С. Р. Лаптева, можно решить за счет подачи Иртышской воды из Омского гидроузла, проектируемого в конце 1930-х годов инженером-геологом К. М.Голубенцевым 4 .

Результатом исследовательских работ стало создание в 1939 году у села Красногорка опытной станции по добыче мирабилита [3].

Параллельно с этим создавались и бальнеологические проекты. Предполагалось, что в 1938 году будет проведено тщательное клинико-курортологическое изучение местности вокруг озера, и выбрано место строительства курорта. В период с 1939 по 1942 год планировалось построить на его берегу физиолечебницу, поликлинику, два корпуса на 200 больных, ванное здание на 40 ванн, а также несколько жилых и подсобных помещений 5 . По неизвестным причинам, эта идея не была реализована.

В сентябре 1941 года на озере работала бригада Научно-исследовательского института галлургии с целью проектирования сульфатного завода на восточном берегу, и с использованием Сагского залива в качестве естественного бассейна. Посетивший озеро в это же время инженер К.М. Голубенцев отмечал, что следует возвести вокруг озера каскад из 24-х плотин, обеспечивающих аккумулирование в логах вод осеннего стока. По его мнению, в особо снежные годы эффективность бассейнового способа добычи мирабилита может быть снижена из-за разубоживания рапы. К тому же такая добыча носила ярко выраженный сезонный характер. Его предложение состояло в том, чтобы не использовать залив, а разбить все озеро на искусственные бассейны (отсеки) из шпунтовых рядов площадью в 1 км² каждый. Внутри ряда с помощью переборок создать более мелкие бассейны, производя перекачку рапы из одного бассейна в другой в разное время года, и выделяя из нее последовательно сульфат натрия, поваренную соль, соли магния и бром. Доставку этих ресурсов из озерной акватории на завод могут обеспечить предлагаемые им для создания канатная или монорельсовая дороги

Идеи К. М. Голубенцева приняты не были, хотя наиболее крупные лога вокруг озера в скором времени перекрыли плотинами и создали в них водохранилища - Амринскую и Ксеньевскую балки.

${ }^{4}$ Лаптев С.Р. Пути производственного освоения озера Эбейты. // Омская область. Орган Омского областного исполнительного комитета Советов. - 1939, № 9, с. 46-54.

${ }_{5}^{5}$ Вальтер Е.Б. Перспективы лечебного дела в области. // Омская область. Орган Омского областного исполнительного комитета. Ежемесячный общественно-экономический журнал, 1937, № 6, с. 67-70.

${ }^{6}$ Голубенцев К. М. Соображения по эксплуатации озера Эбейты. // Государственный исторический архив Омской области. Ф. 2043, оп. 1, д. 1, лл. 2, 2 об., 3, 3 об., 5, 5 об., 7, 7 об., 10, 10 об., 14 об. 
Полноценная разработка мирабилита началась в 1942 году и продолжалась в течение семи лет. Добычу в объеме 10 тыс. т сульфата натрия в год вела сульфатная артель. Соль вывозили к Транссибирской железной дороге и впоследствии использовали в химической промышленности (для создания боеприпасов, медикаментов и т.п.). Гужевого транспорта не хватало. Был предложен проект узкоколейной железной дороги, но из-за отсутствия средств проект не был реализован.

С 1948 по 1951 год, в момент прекращения добычи, Эбейтинской партией Западно-Сибирского геологического управления при участии Всесоюзного научно-исследовательского института галлургии на озере были проведены основательные и достоверные геологоразведочные работы, направленные на создание сульфатного комбината. Однако и этот проект был окончательно отклонен. Наблюдения за солевыми запасами водоема стали нерегулярными, а к 1970-му году и вовсе прекратились [3].

Но озеро продолжало изучаться как перспективный объект для бальнеологическогго использования. Проведено множество медицинских исследований, подтвердивших перспективу грязелечения целого ряда заболеваний.

Активная антропогенная деятельность велась вокруг озерной котловины: распашка целинных и залежных земель, снегозадержание, строились дамбы.

В 1979 году впервые озеро Эбейты объявлено гидрологическим памятником природы с ограничением природопользования в его котловине.

Уникальные природные свойства озера привлекали организованные группы туристов, и стали объектом к проведению на нем физико-географических практик студентов Омского государственного педагогического института.

В 1990-х годах начинается новый этап вовлечения озера Эбейты в орбиту хозяйственной деятельности. Так 1999-м году было предложено включить озеро Эбейты в концепцию развития туризма Омской области [5]. С 1998 по 2000 годы геологи Омской геологоразведочной экспедиции провели комплекс топографических работ по разбивке проектных профилей с целью проведения бурения и зондирования донных отложений. С 2001 года началось использование биологического сырья: добыча рачка Artemia Salina для кормов глубокой переработки. С 2009 года на озеро Эбейты и Амринскую балку начинают организовываться регулярные экскурсионные выезды, превратив его в одно из самых популярных направлений регионального туризма.
С 2006 года вследствие изменения экологического законодательства озеро утратило статус гидрологического памятника природы, что впоследствии сказалось на его экологическом состоянии. После проведения научных наблюдений общественными организациями в 2012 году [4] Эбейты стало государственным природным заказником регионального значения. Согласно утвержденному положению в заказнике допускается организовывать экологическое образование, экологическое просвещение и развитие познавательного туризма. Благодаря новому статусу удалось решить две главные проблемы: 1) прекратить незаконную добычу рачка Artemia Salina; 2) ликвидировать траншею длиной 6 км, образовавшуюся в котловине озера в начале 2000-х годов из-за извлечения труб, и задерживающую до 1 млн. $\mathrm{M}^{3}$ воды поверхностного стока.

В течение последних лет озеро Эбейты, окружающая его озерная котловина и Амринская балка (бывший приток в озеро, ныне - комплексный заказник регионального значения) рассматривались как одно из наиболее перспективных мест для развития экологического туризма: проложена экологическая тропа, обустроенная малыми архитектурными формами, обеспечивающими информационную поддержку экскурсантам, самостоятельно посещающим озеро. В 2020-м году посетителей тропы стали обслуживать гиды-волонтеры.

На наш взгляд, вся история проектной деятельности на озере Эбейты - это не просто история государственных и частных инициатив. Это история переосмысления видов хозяйственной деятельности, вектор которых был направлен от опасных для экосистемы озера направлений деятельности (добыча мирабилита, создание дамб и т.п.) до проектов рационального природопользования и охраны природы (создание комплексного заказника, экологической тропы, организованная туристско-экскурсионная деятельность). Следующим этапом должны стать проекты по улучшению состояния прилегающих к котловине озера степных ландшафтов, и в особенности балок и населенных пунктов. Рациональное природопользование должно опираться на качественные научные исследования, проведенные с применением передовых методик изучения подобного рода озер, и их природных циклов, например, закономерностей в изменении площадей водного зеркала [1].

Решение экологических и социальных проблем озера Эбейты и прилегающих к нему поселений необходимо учитывать в программах развития южных районов Омской области. 


\section{ЗАКЛЮЧЕНИЕ}

За более чем сто лет хозяйственной эксплуатации ресурсов озера Эбейты на него было оказано серьезное антропогенное воздействие. Исходя из этого, мы считаем, что приоритетной повесткой на XXI век будет эколого-ориентированное проектирование, где важнейшим условием станет сохранение за озером природоохранного статуса. Мелководный бассейн в условиях аридных степей весьма уязвим к антропогенным воздействиям, реагируя изменениями круговорота вещества и энергии. Не исключено, что для его сохранения потребуется наложить ограничения на сельскохозяйственную деятельность и на строительство коммуникаций. Многообразие антропогенной деятельности, осуществляемой по периметру водоема, опыт реализации предшествующих хозяйственных проектов делает озеро Эбейты уникальной площадкой для понимания природных процессов, происходящих на акватории аналогичных озер в пределах азиатской степной полосы России. Возможно, в скором времени, придет осознание необходимости глубокого изучения озера и его окрестностей как трансформированной экосистемы, что послужит причиной реализации инновационных проектов в области научных исследований и наблюдений, экологического образования, просвещения и восстановления естественных природных экосистем. Эти проекты должны будут запустить процесс интенсивного экономического и социального развития юго-западной части Омской области.

\section{СПИСОК ЛИТЕРАТУРЫ}

1. Вахнина И. Л., Носкова Е. В., Голятина М. А. Особенности изменения площадей водного зеркала и количества озер степной зоны Восточного Забайкалья // Вестник Воронежского государственного университета. Серия География. Геоэкология, 2020, № 3, с. 13-23. DOI: https://doi.org/10.17308/geo.2020.3/3019.

2. Демешко В.Н. История рекреационного освоения озера Эбейты // Материалы XIII Международной научно-практической конференции «Омские сочиально-гуманитарные чтения», 2020, с. 194-199.

3. Кривонос Л.М., Лустова Т.Н. Озеро Эбейты уникальное комплексное месторождение минеральных солей и лечебных грязей // Люди и недра: история геологического изучения и освоения недр территории Омской области / Под ред. И.А. Вяткина. Омск: Омское книжное издательство, 2011, с. 192-197.

4. О состоянии и охране окружающей среды Омской области в 2011 году / Министерство природных ресурсов и экологии Омской области. Омск: Издательский дом «Наука», 2012. 198 с.

5. Фалькович Н. С. К вопросу о концепции туризма в Омском Прииртышье // Материаль межрегиональной научно-практической конференции, посвященной 90-летию со дня рождения Д. Н. Фиалкова и 75-летию ВООП «Природа и природопользование на рубеже ХХІ века», 1999, с. 362-366.

Конфликт интересов: Автор декларируют отсутствие явных и потенциальных конфликтов интересов, связанных с публикацией настоящей статьи.

Поступила в редакциию 12.03.2021 Принята к публикащчи 23.11.2021

\title{
THE REVIEWS, CHRONICLES, DATA
}

\section{History of the Economic Development of the Ebeity Lake}

\author{
V.N. Demeshko $\bowtie$ \\ Omsk State Pedagogical University, Omsk, Russia \\ (14, Tukhachevsky Naberezhnaya Str., Omsk, 644043)
}

Abstract: The purpose of this study is to trace the sequence of study, design and management activities on Ebeity Lake from the first half of the 20th century to the present, identifying the timing of major changes

(C) Demeshko V.N., 2021

\ Vitaly N. Demeshko, e-mail: demits517@mail.ru

The content is available under Creative Commons Attribution 4.0 License. 
in nature management patterns. The article considers the role of Lake Ebeity in the economic activity of the Omsk Pre-Irtyshye. The subject of the research is the realized and unrealized projects and ideas on the use of the lake in industry, transport and recreation sphere, rational nature management. The article presents the geographical parameters of the lake and indicates its natural resources. It summarizes the development of projects and ideas as the lake's water area, nature and ecological condition are explored. The key stages of change in the nature and vector of natural resource use are highlighted. The results show the extent to which the lake has been involved in economic activities at different historical epochs, as well as changes in the types of natural resource use as environmental problems have arisen. Particular attention is paid to the pre-war stage of its study, preparation for exploitation, and extraction of minerals during the Great Patriotic War, as it was at that time that the lake was subjected to the greatest anthropogenic impact. In later times, the lake has become a site for nature conservation and tourist and recreational activities, and one of the most promising sites for eco-tourism design. The study of the design history of the Ebeity Lake allows a better understanding of the anthropogenic processes taking place in the bitter-saline lakes of the steppe strip of the Russian Federation. It also contributes to better spatial planning, and in the future may serve as a basis for the formation of the concept of rational nature management and sustainable development of similar water areas, adjacent settlements, industrial, transport and recreational infrastructure.

Key words: design, natural resources, lake, environmental management, wildlife sanctuary.

For citation: Demeshko V.N. History of the Economic Development of the Ebeity Lake. Vestnik Voronezskogo gosudarstvennogo universiteta. Seria: Geografia. Geoekologia, 2021, no. 4, pp. 100-105. (In Russ.) DOI: https://doi.org/10.17308/geo.2021.4/3756

\section{REFERENCES}

1. Vakhnina I.L., Noskova E.V., Golyatina M.A. Osobennosti izmeneniya ploshchadey vodnogo zerkala i kolichestva ozer stepnoy zony Vostochnogo Zabaykal'ya [Features of changes in the areas of the water mirror and the number of lakes in the steppe zone of Eastern Transbaikalia]. Vestnik Voronezhskogo gosudarstvennogo universiteta. Seria Geografia. Geoekologia, 2020, no. 3, pp. 13-23. (In Russ.) DOI: https://doi.org/10.17308/geo.2020.3/3019.

2. Demeshko V.N. Istoriya rekreatsionnogo osvoeniya ozera Ebeyty [The history of recreational development of Lake Ebeyty]. Materialy XIII Mezhdunarodnoy nauchno-prakticheskoy konferentsii «Omskie sotsial'no-gumanitarnye chteniya», 2020, pp. 194-199. (In Russ.)

3. Krivonos L. M., Lustova T. N. Ozero Ebeyty - unikal'noe kompleksnoe mestorozhdenie mineral'nykh soley $\mathrm{i}$ lechebnykh gryazey [Lake Ebeyty is a unique complex deposit of mineral salts and therapeutic mud]. Lyudi $i$ nedra: istoriya geologicheskogo izucheniya i osvoeniya nedr

\section{Демешко Виталий Николаевич}

кандидат географических наук, доцент кафедры географии и методики обучения географии факультета естественнонаучного образования Омского государственного педагогического университета, г. Омск, Российская Федерация, ORCID: 0000-0002-0071-1019, e-mail: demits517@mail.ru territorii Omskoy oblasti / Pod red. I.A. Vyatkina. Omsk: Omskoe knizhnoe izdatel'stvo, 2011, pp. 192-197. (In Russ.)

4. O sostoyanii i okhrane okruzhayushchey sredy Omskoy oblasti v 2011 godu [On the state and environmental protection of the Omsk region in 2011]. Ministerstvo prirodnykh resursov i ekologii Omskoy oblasti. Omsk: Izdatel'skiy dom «Nauka», 2012. 198 p. (In Russ.)

5. Fal'kovich N.S. K voprosu o kontseptsii turizma v Omskom Priirtysh'e [On the issue of the concept of tourism in the Omsk Irtysh region]. Materialy mezhregional'noy nauchno-prakticheskoy konferentsii, posvyashchennoy 90-letiyu so dnya rozhdeniya D. N. Fialkova i 75-letiyu VOOP «Priroda i prirodopol'zovanie na rubezhe XXI veka», 1999, pp. 362-366. (In Russ.)

Conflict of interests: The author declares no information of obvious and potential conflicts of interest related to the publication of this article.

Received: 12.03 .2021

Accepted: 23.11.2021

Vitaly N. Demeshko

Cand. Sci. (Geogr.), Associate Professor of the Department of Geography and Geography Teaching Methods, Faculty of Natural Science Education, Omsk State Pedagogical University, Omsk City, Russian Federation, ORCID: 00000002-0071-1019, e-mail: demits517@mail.ru 